\title{
Management of congenital muscular toticollis Under one year of age
}

\author{
Abdul Matin ${ }^{1}$, Md. Rafiqul Islam², Ranjit Ranjan Roy ${ }^{3}$, Bijoy Krishna Das ${ }^{4}$ \\ Sudesh Chandra Rakshit ${ }^{5}$, Rita Khan ${ }^{6}$
}

\begin{abstract}
Summary:
Background and study aim:

Torticollis is the postural deformity of head and neck. Congenital Muscular Torticollis (CMT) is a postural deformity of head and neck detected at birth or shortly after birth, primarily resulting from unilateral shortening of Sternocleidomastoid muscle (SCM), In neonates and infants, patient may cure conservatively by physiotherapy but surgery is the treatment of choice for children and adolescents. Here we show our experience regarding management of congenital muscular torticollis with physiotherapy.
\end{abstract}

Patients and Methods:

This is an observational descriptive study. Verbal consent from parents was taken. Patients of congenital muscular torticollis with other disease or other congenital anomaly were excluded from study. Twenty patients of congenital muscular torticollis were treated. The cases were enrolled between Nov' 2005 to Oct' 2008 in Bangabandhu Sheikh Mujib Medical University, Gonosasthaya Somaj Vittik Medical College Hospital, ZH Sikder Women's Medical College Hospital, Shaheed Shurawardy Medical College Hospital. Neonates and infants were treated conservatively with physiotherapy and non responsive cases were referred for surgery.

Results:

Patients age range from 5 days to 1 year of which eleven were females and nine were males. Sternocleidomastoid muscle (SCM) was shortened in all cases (12 on right side and 8 on left side). Of 20 patients 6 neonates, rest 14 infants within 1 year age. Out of 20 neonates and infants 17 were cured conservatively with physiotherapy and rest 3 were referred for surgery. Conclusion: Most of the patient of congenital muscular torticollis can be treated conservatively during infancy.

Key words: Congenital Muscular torticollis (CMT), Wryneck, Conservative Management, Manual Stretching,

\section{Introduction:}

Torticollis is the postural deformity of head and neck which may be acquired or congenital. There are

1. Assistant Professor,Department of Pediatrics ,Shahid Shurawardy Medical College and Hospital, Dhaka, Bangladesh

2. Assistant Professor.Department of Pediatrics .Shahid Shurawardy Medical College and Hospital, Dhaka, Bangladesh

3. Associate Professor, Department of Pediatrics ,Shahid Shurawardy Medical College and Hospital, Dhaka, Bangladesh,Dhaka

4. Associate Professor and Head, Department of Pediatric Surgery, Z H Sikder Women's Medical College, Dhaka, Bangladesh.,

5. Assistant Professoe, Dept. of Paediatrics,Shahid Shuhrawardy Medical

College.

.6. Medical officer, NICR\&H Mohakhali Dhaka

Correspondence

Dr. Abdul Matin, Assistant Professor, Department of PediatricsShaheed

Shurawardi Medical College and Hospital, Dhaka, Bangladesh. various types of congenital torticollis. Congenital Muscular torticollis (CMT) is a postural deformity of head and neck detected at birth or shortly after birth, primarily resulting from unilateral fibrosis \& shortening Sternocleidomastoid muscle ${ }^{1-2}$. The shortening of Sternocleidomastoid muscle (SCM) results in traction of mastoid process toward the sternoclavicularjoint ${ }^{3}$ The head is therefore rotated \& tilted toward the involved Sternocleidomastoid muscle. The condition is some times called "Wryneck". Torticollis is also known as twisted neckThe incidence of Congenital Muscular torticollis (CMT) is one in every 300 live births ${ }^{4}$. Plagiocephaly may co-exist in $80-90 \%$ of children with $\mathrm{CMT}^{1,5}$

Though impairment of Sternocleidomastoid muscle (SCM) function is the most frequent cause of CMT but torticollis could also be result from other underlying disorders. The exact pathophysioiogy and etiology of sternocleidomastoid impairment in CMT still unknown. In Congenital Muscular torticollis (CMT) patient's head 
remain tilted toward the involved side. Child and adolescents patient can't look forward. If the patient wants to look other sides he/she have to rotate whole body as he / she can't move the neck. Gradually patient develops facial hemihypoplasia which results in flattening and under development of the malar eminence, downward displacement of the eye, ear and angle of mouth on the effected side. It also hampers the development of facial skeletons.

Children with Congenital Muscular torticollis (CMT) can be assigned to one of three groups ${ }^{1}$.

1. Children with a palpable swelling or pseudo tumor of the sternocleidomastoid,

2. Children with sternocleidomastoid (SCM) tightness but no tumor,

3. Children with all features of muscular torticollis without muscle tightness or tumor. Diagnosis can do by history, physical examination \& clinical progression but in some cases ocular, neurological evaluation and radiological investigation of cervical spine is necessary ${ }^{6}$.

Management depends upon the age of patient. Patient of below 1 year of age, treatment is conservative Physiotherapy and above one year of age - treatment is surgery. Within one year of age 69 to $91 \%$ patient may cure conservatively with physiotherapy ${ }^{1,7,8}$.

Conservative management of infants with torticollis consists of positioning, gentle range of motion, and strengthening through activation of head and trunk muscles as the infant gains control of upright postures. ${ }^{9,10}$ Manual stretching is the most common form of treatment for $\mathrm{CMT}^{10}$. Proper stabilization and hand placement is vital for the success of each stretch; however, all child/parent pairs will not be comfortable with the same method of stretching or the same stretch positions. The severity of the torticollis, the age of the child, the tolerance of the child for handling, and the parent's ability to carry out the exercise program will determine the method of stretching. When performing stretching exercises, the position of the head and neck in flexion versus extension will impact the effectiveness of the stretch ${ }^{9}$.

\section{Materials and methods}

This is an observational descriptive study. Verbal consent from parents was taken. Patients of congenital muscular torticollis with other disease or other congenital anomaly were excluded from study. Data was collected by self administered pre-tested semi structured questionnaire. Twenty cases of Congenital Muscular Torticollis (CMT) were treated from Nov' 2005 to Oct' 2008 in Bangabandhu Sheikh Mujib Medical University, Gonosasthaya Somaj Vittik Medical College Hospital, ZH Sikder Women's Medical College Hospital, Shaheed Shurawardy Medical college Hospital Bangladesh were included in the study. Patients were diagnosed clinically. All the patients present with short sternocleidomastoid muscle. There were no facial hemihypoplasia or any other associated abnormalities. All the cases were treated conservatively with physiotherapy as out patient - none was admitted. Physiotherapy is simple manual stretching of affected sternocleidomastoid, frequent movement of head on opposite direction of head position, lied lateral position on effected side. Patient's mother was trained accordingly. Physiotherapy was given at home by mother.

\section{Results:}

Total 20 patients were selected. Range of age was from 5 days to 1 year. Eleven were female and nine male. SCM was shortened in all cases (12 on right side and 8 on left side) Right: Left $=1.5: 1$. Among them neonates 6 and infants 14 within 1 year of age. There was no associated anomaly. Fifteen patients had the history of normal vaginal delivery, one patient had the history of forceps delivery and four had the history caesarian operation. Among the normal vaginal delivery patients, Six have prolonged labor of which four was first issue. (Table-l).

Table-1: Mode of delivery

\begin{tabular}{|l|l|}
\hline Mode of delivery & No of Patients \\
\hline Caesarian Section & 4 \\
\hline Normal Vaginal Delivery & 15 \\
\hline Forceps (First Born Baby) & 1 \\
\hline Total & 20 \\
\hline
\end{tabular}

None can give the history of breech delivery. Antenatal history was uneventful. There is no family history of torticollis in any patient. Out of 20 neonates and infants 17 cured conservatively with physiotherapy (Table-ll).

Table- II: Treatment Result

\begin{tabular}{|l|l|l|}
\hline $\begin{array}{l}\text { Outcome of } \\
\text { physiotherapy }\end{array}$ & $\begin{array}{l}\text { No of patient } \\
\text { treated of treated }\end{array}$ & $\begin{array}{l}\% \text { of } \\
\text { patient }\end{array}$ \\
\hline Cured & 17 & $85 \%$ \\
\hline Failed & 03 & $15 \%$ \\
\hline Total & 20 & $100 \%$ \\
\hline
\end{tabular}

Total 03 failed with physiotherapy due to non compliance with physiotherapy and were referred for treated 
surgically.

\section{Discussion:}

Congenital Muscular Torticollis (CMT) patient's head always remain tilted to the affected side, they can't look forward, can't rotate the head and neck as they want. They have to move the whole body to see the side objects. Untreated cases develop mandibular hypoplasia, facial hemihypoplasia, skeletal deformity of face, etc which leads to permanent disfiguration. So Congenital Muscular Torticollis (CMT) patients suffer both functional and cosmetic problems. Though in literature, the incidence of CMT is 1 in every 300 live births $^{4}$, but we have no data about CMT in Bangladesh. The optimal management of Congenital Muscular Torticollis (CMT) has been urged for many years. Most agree that physiotherapy is the mainstay of the treatment. In literature success rate of physiotherapy is 69-91 \%.1 In our study it is 85\% which is within the limit of international studies.

Surgery is usually reserved for patients whose conditions were persistent beyond the age of one year or failed with physiotherapy or when cervical function and facial deformities are unacceptable ${ }^{11}$.

Movement of the head and neck depends upon the synergistic and antagonistic activities of the different cervical muscles, such as splenius capitis, trapezius, platysma, the longus coli, the longus capitis, rectus capitis, etc ${ }^{15}$. So, in absence of Congenital Muscular Torticollis (CMT) in one side will not interfere with the movement of head and neck.

In our study, Right : Left $=1.5: 1$ which corresponds with the study of others ${ }^{16}$. There are records of family history of CMT in 3.6\% 16 but we have no such finding which also corresponds with the study of others $^{17}$. Facial asymmetry and plagiocephaly are common, though not invariable associated anomaly with CMT. Both believed to be secondary to the Torticollis. Reported co-existence of hip dysplasias with CMT varies from $0.6 \%$ to $20 \%{ }^{16}$ but we have no such condition or any other associated anomalies like others ${ }^{17}$. Though in reported literature recurrent torticollis is about $3 \%{ }^{19}$ but we have no such record.

\section{Conclusion}

Early detection and initiation of physical therapy is related to improved outcomes and less need for surgical treatment of the SCM. Repositioning is a required element of early management of torticollis. Most of the patient of congenital muscular torticollis can be treated conservatively during infantile period.
Beyond the age of one year and failed cases surgery is the treatment of choice. Limitation of this study is small sample size. Further study with large sample size is advocated. To find out the burden of CMT or CMT with other congenital abnormality prevalence study can done in community.

\section{References:}

1. Cheng JCY, Tang SP, Chen TMK, et al. The clinical presentation and outcome of treatment of congenital muscular torticollis in infants. A study of 1,086 cases. J Pediatr Surg 2000;35: 1091-1096.

2. Canale ST, Griffin DW, Hubbard CN. Congenital muscular torticollis: a long term follow-up. J Bone Joint Surg [Am] 1982;64:810-816.

3. Wolfort PG, Kanter MA, Millar LB. Torticollis, Plastic Recostr Surg .1989:84:682-692.

4. Clarren SK, Smith DW, Hanson JW. Helmet treatment for plagiocephaly and congenital muscular torticollis. J Pediatr 1979;94:43-46.

5. Cheng JCY, Au AWY. Infantile torticollis: a review of 624 cases. J Pediatr Orthop 1994:14:802-807.

6. Thomsen JR, Koltai PJ. Sternomastoid tumor of infancy. Ann Otol Rhinol Laryngol 1989; 98: 955-959

7. De Chalain TMB, KatzA. Idiopathic muscular torticollis in children : the Cape Town experience. Br J Plastic Surg 1992: 45: 297 - 301.

8. Binder H, Eng GD, Gaiser JF, et al. Congenital muscular torticollis: results of conservative management with long-term follow-up in 85 cases. Arch Phys Med Rehabil 1987;68:222225.

9. Karmel-Ross K. Torticollis: Differential Diagnosis, Assessment and Treatment, Surgical Management and Bracing . Binghamton, NY: Haworth Press; 1997.

10. Shepherd R. Torticollis. In: Shepherd R, ed. Physiotherapy in Pediatrics , 3rd ed. Woburn, MA: Butterworth- Heinemann; 1995:293- 302.

11. Hihrschl RB, Sternomastoid torticollis, in Spitz L, Coran AG, editors. Rob \& Smith's Operative surgery Pediatric Surgery. 5th ed, Chapman and Hall, 2-6 Boundary Row, London SE1 8HN, UK. 1995: 71-75.

12. Loder RT The cervical spine. In: Morrissy RT, Weinstein SL, eds. Lovell and Winter's Pediatric Orthopedics , 5th ed. Philadelphia: Lippincott Williams \& Wilkins; 2001:799-836.

13. Stassen LF, Kerawala CJ. New surgical technique for the correction of congenital muscular torticollis. $\mathrm{Br} \mathrm{J}$ Oral Maxillofac Surg 2000:38:142-147.

14. Burstein F, Cohen S. Endoscopic surgical treatment for congenital muscular torticollis. Plast Reconstr Surg 1998:101:20-24.

15. Williams PL, Warwick R. Editors, Myology, Gray's Anatomy. 36th ed, Churchill Living Stone, UK. 1980: 536 547.

16. Ling CM, Balachandran N. A prospective study of Sternomastoid tumour in a closed community. Proceedings of the Tenth Singapore-Malaysia Congress of Medicine 1975; 10:233-6.

17. Freed SS, Coulter-O'Berry C. Identification and Treatment of Congenital Muscular Torticollis in Infants. JPO 2004; 16: 18- 
23.

18. Davids JR, Wenger DR, Mubarak SJ , Congenital muscular torticollis: sequela of intrauterine or perinatal compartment syndrome, J Pediatr Orthop 1993, 13: 141147.

19. Wirth CJ, Hagena FW, Wuelker N, Siebert WE. Biterminal Tenotomy for the treatment of congenital muscular torticollis. J Bone Joint Surg [Am] 1992; 74: 427432. 